School. He then became a science student at University College, Bristol, and graduated from there in 1895. He spent two post-graduate years as an 1851 Royal Exhibition Scholar working under the late Prof. A. P. Chattock, for whom he has always retained warm feelings of admiration and affection, and a third year under Prof. Nernst at the Institut für physikalische Chemie in the University of Göttingen. During 1898-1900 he was a demonstrator in physics at the University of Manchester, and he recalls with pride that Sir Arthur Eddington was one of his students there. Milner left Manchester to take up a lectureship in physics at Firth College, later the University of Sheffield, under Prof. W. M. Hicks, who was successively principal of the College and the first vice-chancellor of the University, so that much of the work and organization of the department fell to Milner's lot. During the War of 1914-18 he served as assistant radiographer to the Third Northern General Hospital until 1917, when he was appointed acting professor of physics, on Prof. Hicks vacating the chair. Since 1921 he has been professor of physics, and in 1922 he was elected to the fellowship of the Royal Society.

In his research activities, Prof. Milner has shown himself to be a physicist in the widest sense, his researches having ranged over many fields, only some of which can be mentioned here. His earliest work was on the thermal conductivity of water (with Prof. Chattock). Later work was concerned with interference phenomena, with the non-reversible character of the formation of soap films, with the electric discharge in mercury vapour (in which connexion he discovered the principal series of mercury), and with the mechanism of the spark discharge, involving the analysis of lines in a rotating mirror and the characteristics of the oscillatory spark. By his pioneer work on the theory of strong electrolytes he anticipated the work of Debye. His more recent work has been concemed with the properties of the electromagnetic field in four dimensions, especially the theory of tubes of force and action in their four-dimensional aspects, and with the properties of Eddington's wave matrices. An experimentalist of no mean order, Prof. Milner is also a self-made theoretical physicist, so that his approach to theoretical work is always characterized by the physical rather than the purely mathematical outlook. Primarily due to this fact he has the rare ability of presenting intelligibly abstruse advances in modern physical theory to a general scientific audience. Many of his old students now occupy prominent positions in the scientific world, and all who know him or his work will join in wishing him many years of happiness and good health in his retirement.

\section{Dr. W. L. H. Duckworth}

THE election of Dr. Wynfrid Laurence Henry Duckworth to be Master of Jesus College, Cambridge, which was announced on May 28, is a well-deserved recognition of a devotion to the service of his College and University which is well-nigh lifelong. Dr. Duckworth, who is reader in anatomy, went to the
University as a scholar of Jesus College, after receiving his earlier education in Birkenhead and at Dinan, Brittany. He graduated with first-class honours in both parts of the Natural Sciences Tripos in 1892-93, and during 1898-1920 was University lecturer in physical anthropology. His laboratory demonstrations and organization and arrangement of the museum specimens which came within his provinee contributed markedly to placing the Cambridge school in a unique position in anthropological studies ; while so long ago as 1902, Dr. Duckworth's merit as an original thinker and teacher in anthropology were widely recognized on the publication of his two books "Morphology and Anthropology" and "Studies from the Anthropological Laboratory" (Cambridge). In the same year Dr. Duckworth was invited by a committee of the British Association to join the archæological expedition then excavating in Crete, for the purpose of investigating the racial characters of the ancient and modern inhabitants of the island. The report which he eventually produced is still of standard authority on this question. Dr. Duckworth, who was born on June 5, 1870, represented his University on the General Medical Council during 1923-26.

\section{Colonial Development and Allied Co-operation}

Certain matters of no little moment in relation to scientific research and its application to problems of Colonial development were mentioned in the debate on the second reading of Mr. Malcolm MacDonald's Bill to which it was not possible to refer in NATURE of June 1 (see p. 853). Mr. MacDonald had stressed the facilities which the Bill would afford not only in erecting buildings for clinics, hospitals and schools, to which grants under the existing Colonial Development Act are confined, but also in assisting their maintenance after erection, as well as steadily increasing the opportunities for medical and veterin. ary research and of health measures of all kinds. The importance of the assistance in maintenance was more fully brought out by Sir Francis Fremantle, who stressed its importance in relation to education, which he urged should be directed towards the objects which appealed to the natives, namely, agriculture and health. His experience as a sanitary officer in Mesopotamia during the War of 1914-18 brought him into relation with various races whose intelligence - even of the most primitive of them-in malaria prevention after even a short course of instruction had astonished him. After referring to the results and needs of research on leprosy, he went on to point to the achievement on exiguous resources of small hospitals and clinics in Zuzuland. In research he urged that a great deal could be done in regard to the native population, especially in the matter of psychology.

An important aspect of the problems to which research in Africa, for example, will be 'directed was presented by Sir Jocelyn Lucas, who, in speaking of progress in the study of tropical diseases, stressed the importance in this, as well as in other respects, of co-operation with our French Allies. How far the War has fostered co-operation between French and 
British medical and scientific men is indicated by "Medicus M.P. in France" (Lancet, June 1, p. 1031), who speaks of the constant consultations taking place between medical officers of divisions of the two forces and the meetings of French and British consultants, including distinguished civilians, at G.H.Q., at which views are exchanged, leading with numerous other facilities to a far greater degree of co-operation than during 1914-18. This readiness to co-operate and unity of purpose, it may be anticipated with no little confidence, will inspire the co-operation in Colonial administration in the future upon which the two Governments have agreed. Now that the resources of the Belgian Congo and Mandated Territory, upon which the Belgian Government has lavished expenditure, have been placed at the disposal of Belgium's allies, a valuable opportunity has arisen for laying the foundations of future research and co-ordinated action.

\section{Blood-Group Tests and Paternity}

IN view of the application of blood-group tests in medico-legal problems involving disputed bloodrelationship, it is interesting to note results of the test in a series of fifty cases which have been recorded by Dr. David Harley and Dr. G. Roche Lynch (Lancet, May 18, 1940). Most of the cases were affiliation cases; in these, as is well known, the blood test, while not establishing paternity, does eliminate false accusation by establishing non-paternity, the expected rate of establishment on the assumption that all men are falsely accused being approximately 32 per cent. In the present series, non-paternity was established in eight cases, or 16 per cent, a figure which suggests that about half the men were falsely accused, while half were in fact the fathers. The authors point out that while the percentage is not likely to be so high in the 5,000 affiliation cases heard in England and Wales in the course of a year, since in many of them paternity is not in dispute, but merely the amount of compensation, yet the fact that an appreciable number of men prefer to go to prison rather than pay suggests that the number of false accusations is by no means negligible. With improvement in the technique of identifying subgroups, the utilization of these factors should add to the value of the test in such proceedings by raising the percentage of exclusions possible.

\section{National Collections in London or in the Country?}

A MATTER of very great importance to scientific workers in Great Britain and throughout the world is raised by Dr. Percy $R$. Lowe in an article discussing the threatened removal of the ornithological collections from the British Museum (Natural History) to Tring (Museums $J ., 49$; May 1940). It is there stated that "the Trustees of the Museum seriously contemplate transferring the national ornithological collections from South Kensington in London to Tring in Hertfordshire". That would indeed be a serious step, for no expert studies bird skins without using the books referring to the group upon which he is working. So that the ornithological library would have to follow. But many bird papers appear in journals not specifically devoted to ornithology; would the series of these journals also have to go, or would the expert be left in the lurch ? That seems to be a problem not easily solved; Dr. Lowe discusses others. But indeed the proposal bristles with so many difficulties that it may be taken for granted that the Trustees will seek advice from scientific workers who are accustomed to study ornithological or other systematic collections, and will make no decision even for the future without the fullest inquiry and consultation.

\section{The British Pharmacopœia : Emergency Monographs}

THE need for an addendum to the "British Pharmacopœia" which is now ready for official publication was dictated by war-time circumstances which deprived. Great Britain of unfettered access to supplies of cod liver oil and olive oil and made it desirable to sanction the use of substitutes for both. The outstanding new monograph in the Addendum is on oleum vitaminatum, a vitaminized oil which is a solution of vitamins A and D containing 1,000 units of vitamin A activity and 100 units of antirachitic activity (vitamin D) in $1 \mathrm{gm}$. It is clear that the object of the Pharmacopoia Commission was to provide a standard for a substitute for cod liver oil which, in respect of its vitamin contents, should approximate to the natural product. The vehicle for the vitamins may be "a suitable vegetable oil" the choice of which is left to the manufacturer, with the suggestion that arachis oil would answer the purpose at least as well as any other. Provided the preparation responds to the characters and tests for purity laid down in the monograph, vitaminized oil may consist, alternatively, of a suitable fish-liver oil, or blend of fish-liver oils, thus allowing to commercial firms a generous latitude which is justifiable, and indeed advisable, in a time of emergency. Of the nine other new monographs in the Addendum, seven are related to the cod liver oil problem; they include standards for concentrated solutions of vitamins and for emulsions of cod liver oil itself and its substitute.

The only new monograph which is unrelated to cod liver oil is that on tetanus toxoid, which is officially described as "tetanus toxin, the sterile filtrate of a culture on a suitable medium of Clustridium tetani, or material derived therefrom, the specific toxicity of which has been completely removed by the action of chemical substances in such a manner that it retains efficient properties as an immunising antigen". Tetanus toxoid may occur as a simple solution of tetanus toxin or as alum-precipitated tetanus toxoid. The Addendum amends five monographs of the Pharmacopœia. The object of the alterations in some cases, namely, liniment of camphor and compound ointment of mercury, is to authorize the use of arachis oil, cottonseed oil or sesame oil in place of olive oil in making these preparations. In the case of capsicum ointment, the use is sanctioned of a simple ointment prepared with yellow soft paraffin in place of the present base which contains lard. A new formula is presented as a 